\title{
Modified Deloading Strategy of Wind Turbine Generators for Primary Frequency Regulation in Micro-Grid
}

\author{
Dhananjay Kumar $^{1} \cdot$ Pavitra Sharma $^{1}$ - H. D. Mathur ${ }^{1} \cdot$ S. Bhanot ${ }^{1} \cdot$ R.C. Bansal ${ }^{2}$
}

Received: 18 August 2019 / Accepted: 17 March 2020 / Published online: 4 April 2020

(C) Springer Nature Singapore Pte Ltd. 2020

\begin{abstract}
In this work, the contribution of wind turbine generator (WTG) to support micro-grid (MG) during depressed frequency condition has been studied with a modified strategy for improving the primary load frequency response of MG. The majority of existing deloading techniques to estimate the reference power are based on the linear relationship. Hence they are not so accurate to mimic the actual speed versus power dynamics of turbine rotor during deloading operation which is inherently nonlinear in nature. In this work, the existing methods have been analyzed in detail with an aim to improve the performance. Based on the analysis a modified deloading method assuming non-linear relation between rotor speed and power of WTG system has been proposed which shows the improved load frequency response in MG. The proposed deloading technique is simulated and validated using real-time digital simulator (OP4510) for the variation in load and generation inside an islanded MG. The results obtained using modified deloading method are compared with existing deloading method and it is found that proposed deloading method handles the non-linearity of the system during deloading operation and also it contributes more power to MG in response to load demand at the cost of slight increase in the speed of turbine rotor.
\end{abstract}

Keywords Deloading $\cdot$ Variable speed wind turbines $\cdot$ Doubly-fed induction generator $\cdot$ Micro-grid $\cdot$ Primary frequency control

\section{Introduction}

The renewable energy sources (RESs) such as wind and solar are now playing a significant role in supplying a significant share of the electrical needs of the present era [ [1-3]]. In the coming five years, wind is going to represent the largest annual capacity addition for renewable after solar and hydro [4].

\section{R.C. Bansal}

rcbansal@ieee.org

Dhananjay Kumar

djaydelhi@gmail.com

Pavitra Sharma

sharmapavitra334@gmail.com

H. D. Mathur

mathurhd@pilani.bits-pilani.ac.in

S. Bhanot

surekha@bits-pilani.ac.in

1 Department of Electrical \& Electronics Engineering, BITS, Pilani, Rajasthan, India

2 Department of Electrical Engineering, University of Sharjah, Sharjah, United Arab Emirates
The modern power system is under modification process to become smart power system that is robust, adaptive, optimized, intelligent and self-sufficient to take decision during pre-defined conditions for maintaining the system stable while satisfying the need. The variable speed wind turbines (VSWTs) interfaced to grid via power electronics converters reduces the overall inertia of the grid as compared to same sized thermal/hydro units [5]. The energy reserve can be created by operating the wind turbines below maximum power point called deloaded power point [6-10]. After deloading the WTG, a generation margin will be available that can be utilized during depressed frequency conditions in MG. A time sequence simulation technique to evaluate the reliability of a distribution system including WTG as an alternative supply is presented in [11]. In [12], an overview of various wind electric generator (WEG) types has been described focusing mainly on the Type-3A WEG standard model.

The work presented in [13] shows that high inertia $(\mathrm{H}=4 \mathrm{~s})$ of wind turbine-generators (WTGs) can be integrated to provide frequency support during generation outages. Fuzzy logic supervisor based primary frequency control of variable speed wind turbine is presented in [14]. A method using the voltage source converter based high voltage DC connected 
wind farms has been presented in [15] for primary control of frequency in power networks. In [5], the technique of operating variable speed wind turbine generator (DFIG) below maximum power point (deloading) has been studied to create a dynamic energy reserve margin to support primary frequency regulation in microgrids (MGs) during depressed frequency conditions. The study on the impacts of wind power generating system integration to multi-area power system for frequency stabilization with fuzzy logic controller in deregulated environment has been presented in [16]. The application of WTG as one of distributed generation source to deal with power imbalance during islanding based upon islanding security region has been presented in [17]. A work on deloading control strategies of wind generators for power system frequency regulation to improve the deloading control method that enhanced both stability and effectiveness has been presented in [18]. A study and analysis of power system frequency response from fixed speed and doubly fed induction generator based wind turbines is presented in [19]. Coordinated operation of wind turbines and flywheel storage for primary frequency control support to MG has been presented in [20]. The study of load frequency control by participation of wind farms in power Systems has been given in [ [21-24]]. The work presented in [25] explains the economic analysis of reserve management strategies for grid connected wind farms to regulate primary control reserves.

In [26]- [27] the assumption of static deloading is modified by dynamic deloading and is implemented by considering a nonlinear relationship between frequency deviation and deloading percentage using fuzzy logic controller to decide the deloading percentage by taking available wind speed and frequency deviation as an input. The droop setting of the WTG is varied continuously using TS-fuzzy logic control by sensing the prevailing wind speed and deviation in wind speed. In [28], the review of frequency control techniques and inertial response for renewable energy sources has been documented. The conventional generators show automatic inertial response by releasing the kinetic energy stored in their rotating mass, but WTGs lack this facility hence they need a system that will emulate the inertia to extract the kinetic energy stored in the blades of wind turbines and support to the $\mathrm{MG}$ during under frequency conditions. After the frequency events has occurred it is the inertial response which will act first by releasing kinetic energy and then after a few seconds (typically $8-10$ ) the primary controller is activated to regulate the frequency [28]. The analysis of inertial response and primary power frequency control provision by DFIG wind turbines has been presented in [29] for smaller size power system (150 MW-1.5 GW). A modified MPPT control for small wind turbines to provide dynamic frequency support in Islanded microgrid has been presented in [30]. The stochastic modelling of wind and solar PV and stability analysis of MG using robust control synthesis is presented in [31]- [32].
In this work, the mathematical analysis of deloading operation of DFIG based WTG simulation model to support primary frequency regulation in an islanded $\mathrm{MG}$ is presented. The model adopted does not considers the electrical modeling of the synchronous generator and WTG. For simulation purpose, a variable speed wind turbine model (DFIG) is considered for deloading study. Section 2 describes the deloading and maximum power point (MPP) operation of wind turbines in wind energy conversion system. The deloading operation has been reported considering straight line trajectory between maximum power point $P_{\max }$ and deloaded power $P_{d e l}$ is analysed in this section. Section 3 describes the MG model assumed for primary frequency response study. Section 4 explains the issues related with existing deloading techniques and derivation of the proposed deloading equation. The simulation results of the previous and modified deloading method are presented and compared in section 5. The real-time hardware-in-loop (HIL) implementation using Opal-RT realtime simulator (OP4510) has been done for existing and proposed deloading methods. The HIL results of the proposed and existing method have been summarized in section 6 which is followed by the conclusion drawn in section 7 .

\section{Deloading Operation in VSWTs}

Deloading is a concept of shifting the operation of VSWTs below its maximum power point (MPP). The wind turbine should operate on the right sub-optimal curve, to maintain stable operation while providing frequency response over a full range of wind speeds. Figure 1 represents the MPPT and deloading curve and the trajectory of reference power versus speed of wind turbine. The two trajectories represented here is a straight line (S) and a curve (X). Since the measured rotor speed $\left(\omega_{r_{\text {meas }}}\right)$ required for deloaded operation may exceed the maximum value $\left(\omega_{\text {ropt }}\right)$ for medium and high wind speeds, three wind speed modes are defined in terms of the deloaded control objective and secure operation constraints, i.e. (a) low wind speed mode where deloaded operation is accomplished by rotor speed control (b) medium wind speed mode where deloaded operation is conducted by combining pitch angle control and rotor speed control (c) high wind speed mode where modified pitch angle control alone enables the deloaded operation. In case of fixed deloading, the deloading factor $K$ decides the deloaded operating point of WTG which will be a fixed percentage of MPP. Referring to the straight line trajectory [27] in Figure 1 the expression for $P_{d e l}$ is given by equation (1). Considering straight line trajectory $S$ between $A$ and $B$ the reference power with respect to rotor speed is calculated by equation (2). This method follows the linear deloading technique of WTG. 
Fig. 1 Generalized MPPT Curve (solid in red) and deloaded power curve (dotted in blue) with straight line trajectory (S) and curved trajectory $(\mathrm{X})$ for reference power calculation

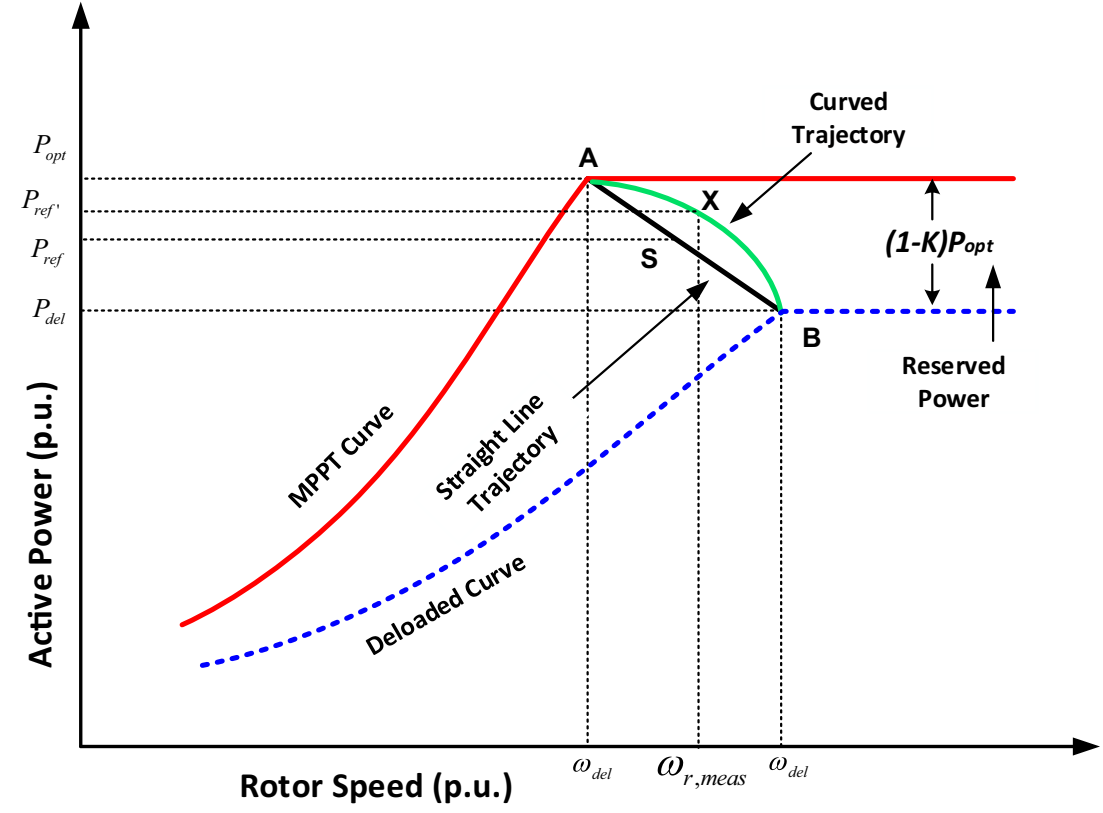

loop for deloading and frequency regulation in $\mathrm{MG}$ is shown in Figure 2.

\section{Microgrid Model}

The MG considered in this work is shown in Figure 3 which consists of renewable energy resource (RES) like WTG, a synchronous machine driven by diesel engine. It consists of four WTGs of 1.5 MW capacity each. The diesel engine driven synchronous machine having capacity of 5 MVA (1 per

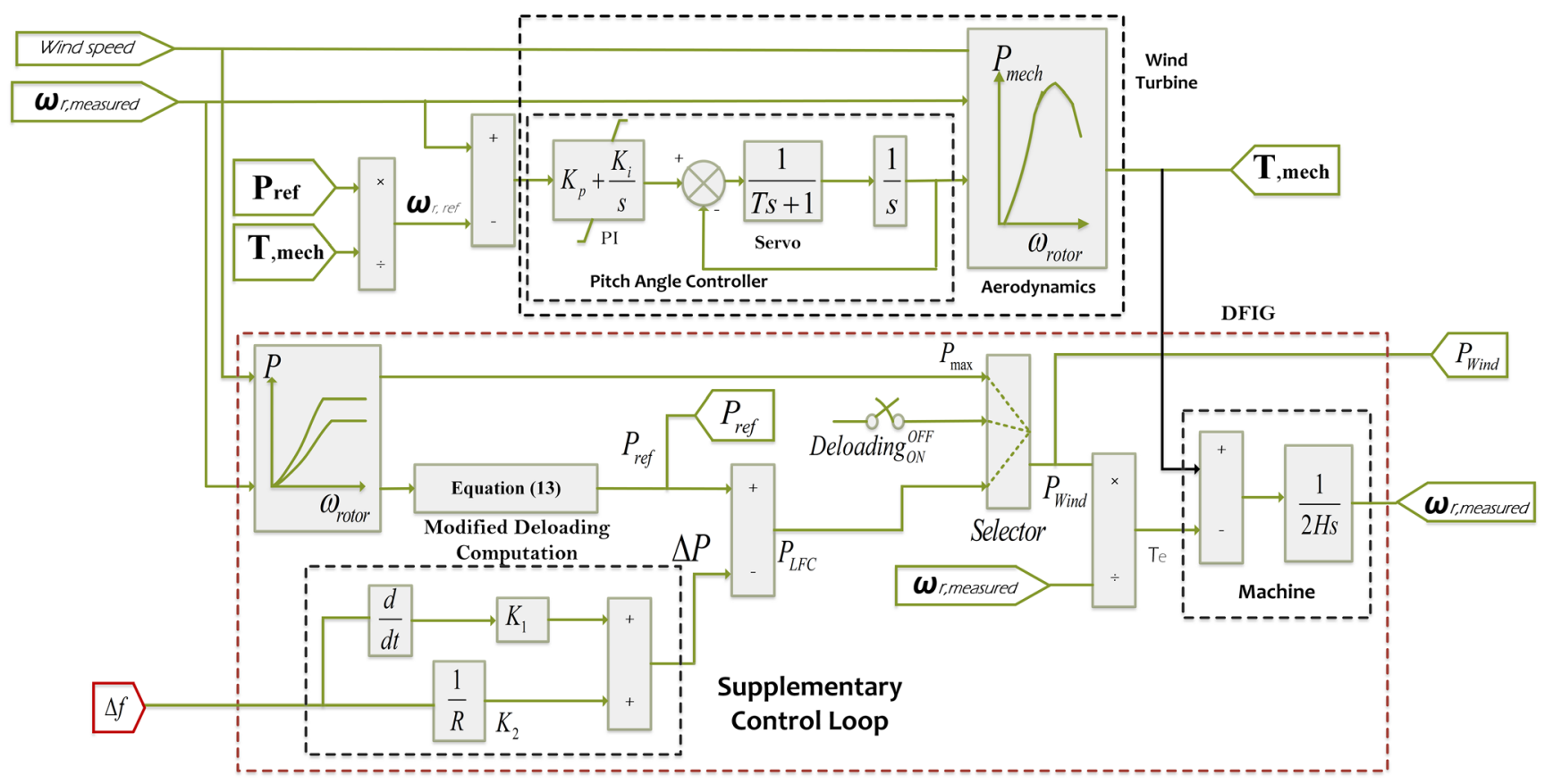

Fig. 2 Simulink diagram for deloading operation of DFIG based WTG and its implementation to MG for primary frequency regulation [5] 


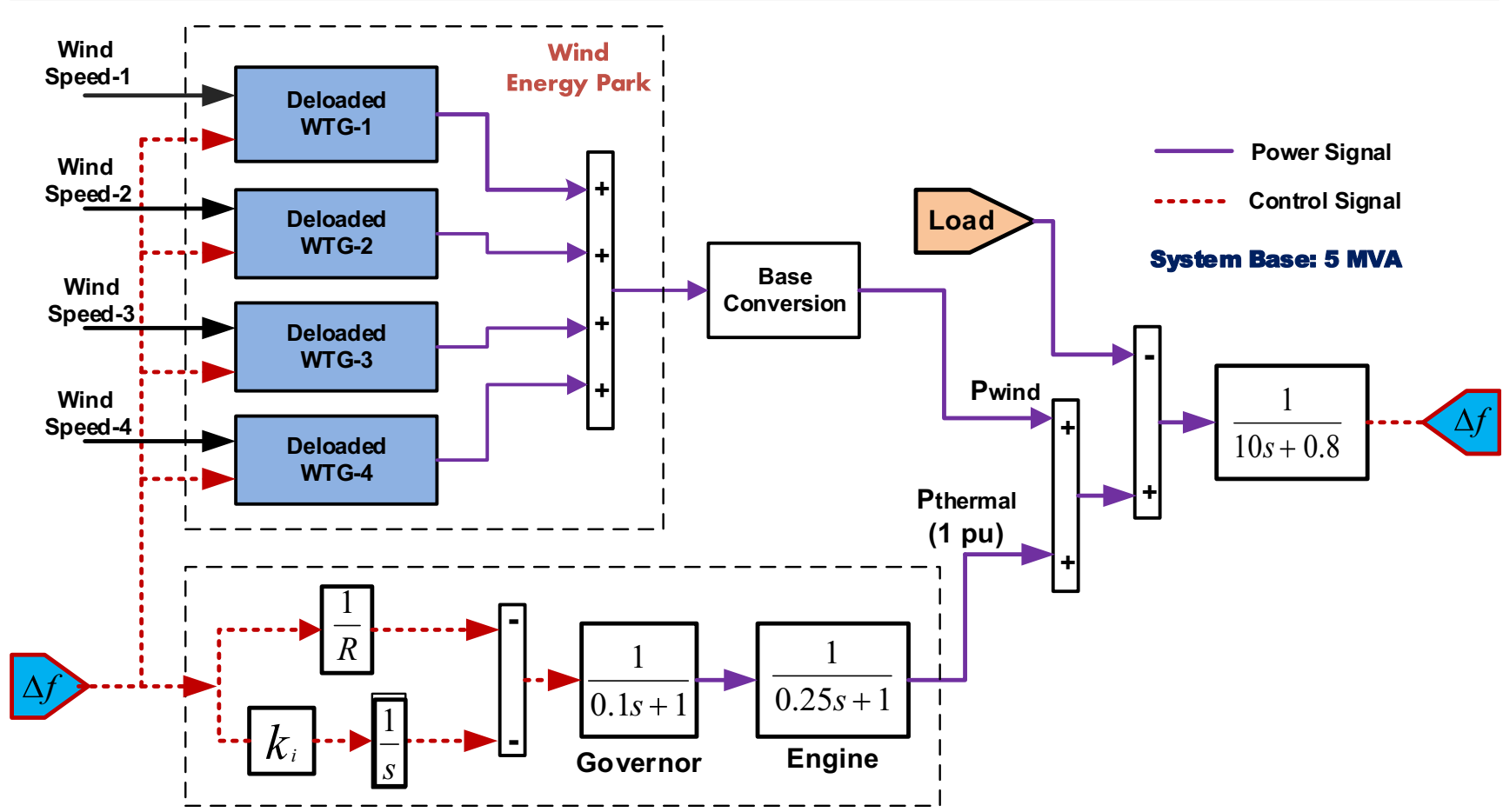

Fig. 3 Simulink diagram for deloading operation of DFIG based WTG and its implementation to MG for primary frequency regulation

unit) in MG is denoted by $G$. The diesel engine based synchronous generator and wind turbine generator have inertia constant (denoted by ' $H$ ', unit MW-seconds/MVA) of $5 \mathrm{~s}$ and $5.04 \mathrm{~s}$ respectively on individual machine base. Assuming the base of the system as 5 MVA the wind turbine and diesel thermal unit inertia can be calculated using equation (3).

In a system where multiple power generating units having speed governor system are operating together, the speed droop parameter $R$ decides the contribution of each unit to a common load. The speed droop is given by equation (4) [33].

$H_{\text {system }}=H_{\text {machine }}\left(\frac{G_{\text {system }}}{G_{\text {machine }}}\right)$

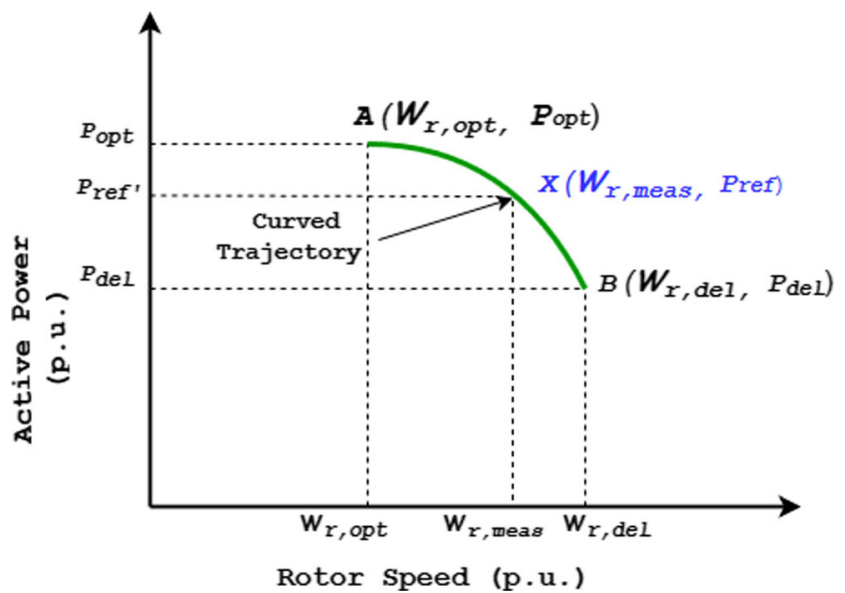

Fig. 4 Curve trajectory to estimate reference power for deloaded WTG by modified deloading method
$R=\left(\frac{\Delta f}{\Delta P}\right) 100$

where $\Delta f$ is the incremental change in frequency per unit (p.u), and $\Delta P$ is the incremental change in power. The droop action changes the reference power of the prime mover whenever there is change in frequency. The typical droop value for the generating units participating in frequency regulation lies between 3 and 6\% [5] and for this study it has been assumed to $6 \%$. The diesel synchronous generator provides power to MG at a constant frequency and it has an integral control loop for regulating the frequency deviations caused due to disturbances occurring in the system. The integral control loop for diesel synchronous generator is shown in Figure 3 with integral time constant $K_{i}$.

\section{Modified Deloading}

\section{Issues with Linear Deloading Technique}

The integral control loop for diesel synchronous generator is shown in Figure 3 with integral time constant Referring to the Figure 1, it can be seen that in deloaded power margin area considering the straight trajectory ' $\mathrm{S}$ ' of the point relating the reference power $\left(P_{r e f}\right)$ with respect to measured rotor speed $\left(\omega_{r_{\text {meas }}}\right)$ will not be accurate to estimate the $P_{\text {ref }}$ for a particular rotor speed. Hence, following the straight line trajectory the estimation of dynamic reserve power margin will be inaccurate and the reserve margin controller will not be able to utilize 
Fig. 5 Turbine rotor speed in response to wind speed change seen by WTG and load change seen by $\mathrm{MG}$

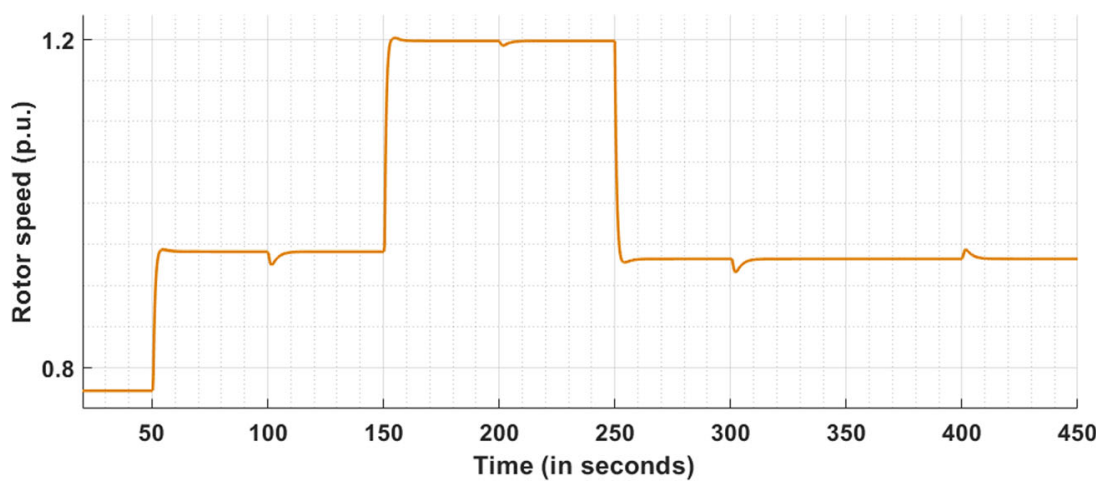

optimum energy reserve at every instant to support the $\mathrm{MG}$ during under frequency events. Hence, there is a need of method to get the closer estimate of the reference power. Consider an actual case when some WTGs of a wind farm are operating with deloaded power strategy at different wind speeds and the under frequency event occurs in MG. Consequently the MG will send a command signal $(\Delta f)$ to deloaded WTG stating that the active power support is required. The WTG responds to this command signal by decreasing the rotor speed of turbine towards optimum value $\left(\omega_{r_{\text {meas }}}\right)$ that results in the variation of reference power and the reserve margin. In real cases, the trajectory followed to move the power point of WTG from deloaded point towards MPP is nonlinear and may be represented by a curve. The curve equation has been derived in section 4.2 to obtain a more accurate estimate of power margin and reference power.

\section{Equation for the Curved Trajectory}

Figure 4 shows the curve joining the optimum power point $A$ $\left(P_{o p t}\right)$ and deloaded power point point $B\left(P_{d e l}\right)$. For analyzing the actual situation, it is assumed as a curve $A X B$, instead of taking the straight line trajectory $\mathrm{S}$ as shown in Figure 1. The co-ordinates of point $A$ and $B$ are $\left(P_{o p t}, \omega_{r_{o p t}}\right)$ and $\left(P_{d e l}, \omega_{r_{d e l}}\right)$ respectively.

Assuming an arbitrary point $X$ on the curved line $A X B$, the co-ordinates of this point $X$ are $\left(P_{\text {ref }}, \omega_{r_{\text {meas }}}\right)$. To estimate the reference power for deloaded WTG the equation of the curve joining $A$ and $B$ has to be derived. The curve $A X B$ is represented by an expression given in equation (5). Putting the co- ordinates of points $A$ and $B$ in equation (5), we get the expression for optimum as well as deloaded power that is given by equation (6) and (7).

$y=a x^{2}+$

$P_{o p t}=a\left(\omega_{r_{o p t}}\right)^{2}+b \omega_{r_{o p t}}$

$P_{d e l}=a\left(\omega_{r_{d e l}}\right)^{2}+b \omega_{r_{d e l}}$

Considering fixed deloading instead of dynamic, the deloading constants for wind power and turbine rotor speed i.e. $K_{1}$ and $K_{2}$ are limited within a range due to restricted capacity of power electronics controlled converters in WTG. Once the deloading constant for wind power and turbine rotor speed i.e. $K_{1}$ and $K_{2}$ are decided, the values of $P_{d e l}$ and $\omega_{r_{d e l}}$ become a constant. The deloading constant for power is $K_{1}$ and for rotor speed is $K_{2}$. The equation (6) expresses the relation between optimal rotor speed versus maximum power and the equation (7) shows the relation between deloaded rotor speed versus deloaded power of WTG. The deloading constant for wind power $\left(K_{1}\right)$ is less than unity and its range for stable operation of WTG is between 0 and 0.2 while the deloading constant for rotor speed lies between 0 and 0.1 [5]. The relation between deloaded and optimal power is expressed in equation (8). Assuming the deloaded curve towards over speeding side (i.e. $\omega_{r_{\text {del }}}>\omega_{r_{\text {opt }}}$ ), the relationship between optimal speed and deloaded speed is given by equation (9). The value for $K_{2}$ is positive since the deloaded speed is greater than speed at optimal power point. Putting the values of $P_{d e l}$ from equation (7) and $\omega_{r_{d e l}}$ from equation (9) in to

Fig. 6 Turbine rotor speed in MG for (a) A load rise from 1.2 p.u. to 1.3 p.u. (b) A load fall from 1.45 p.u. to $1.38 \mathrm{p} . \mathrm{u}$

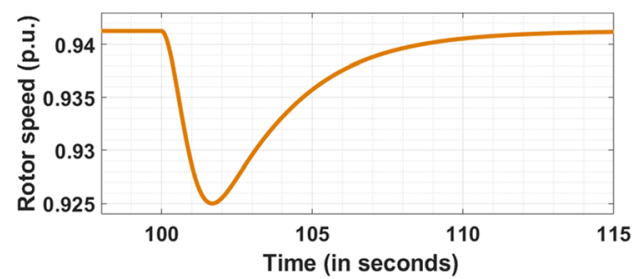

(a)

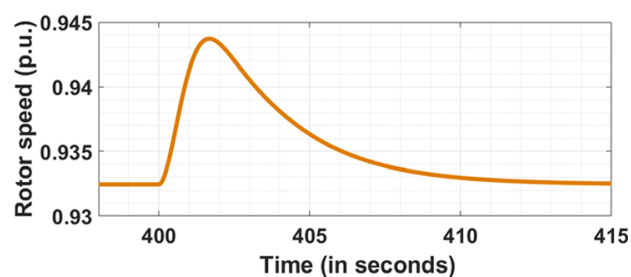

(b) 
Fig. 7 Reference power variation of WTG after $10 \%$ deloading in response to wind speed, load deviation

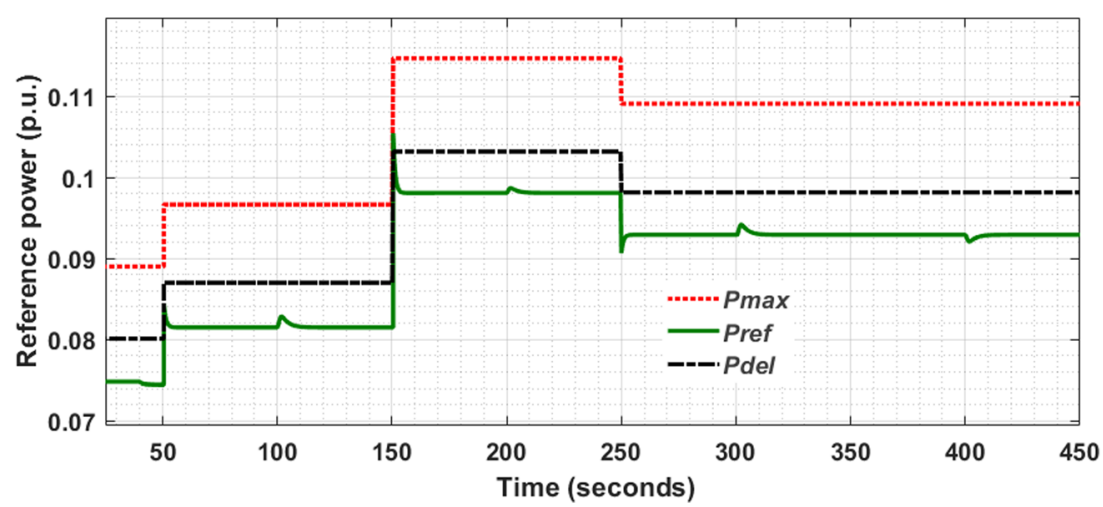

equation (7) results in equation (10). The equations (7) and (10) have now become a pair of simultaneous equation which can be solved to find the coefficients $a$ and $b$.

$$
\begin{aligned}
& P_{d e l}=\left(1-K_{1}\right) \cdot P_{o p t} \\
& \omega_{r_{d e l}}=\left(1+K_{2}\right) \omega_{r_{o p t}} \\
& \left(\mathrm{~K}_{2}-K_{1}\right) P_{o p t}=a\left(1+K_{2}\right)\left\{1+\left(1+K_{2}\right)\right\} \omega_{r_{o p t}}{ }^{2} \\
& a=\frac{P_{o p t}}{\omega_{r_{o p t}}{ }^{2}} \frac{\left(K_{2}-K_{1}\right)}{\left(K_{2}^{2}+3 K_{2}+2\right)} \\
& b=\frac{P_{o p t}}{\omega_{r_{o p t}}} \frac{\left(K_{2}^{2}+2 K_{2}+K_{1}+2\right)}{\left(K_{2}^{2}+3 K_{2}+2\right)}
\end{aligned}
$$
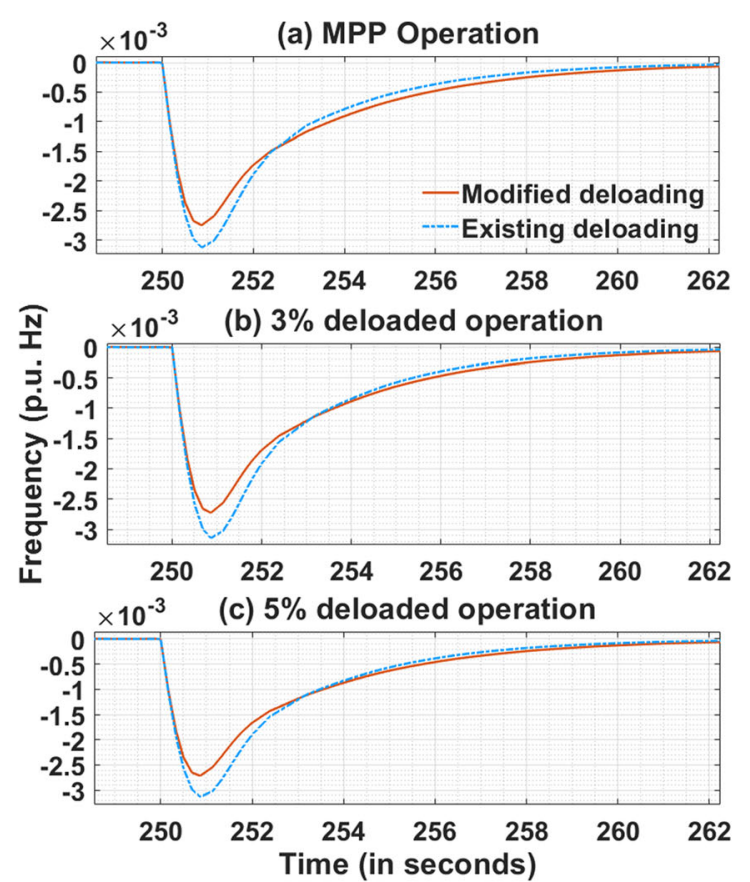

(A)

Fig. 8 Frequency deviation in MG with WTG support by modified deloading and existing deloading method (A) For 10\% load rise during (a) MPP operation, (b) $3 \%$ deloaded operation, and (c) $5 \%$ deloaded
To simplify the equation, let the expression $\left(P_{\text {opt }} / \omega_{r_{\text {opt }}}\right)$ $=Z$ and $\left\{\left(K_{2}-K_{1}\right) /\left(K_{2}^{2}+3 K_{2}+2\right)\right\}=W$ then the coefficients $a$ and $b$ can be rewritten as $a=W Z / \omega_{r_{\text {opt }}}$ and $b=Z(1-W)$ by equation (11) and (12).

$y=\frac{W Z}{\omega_{r_{o p t}}} \cdot x^{2}+Z(1-W) \cdot x$

The general expression for the curved trajectory is derived in equation (13). Putting the value of measured rotor speed $\omega_{r_{\text {meas }}}$, the reference power can be obtained is given by equation (14).
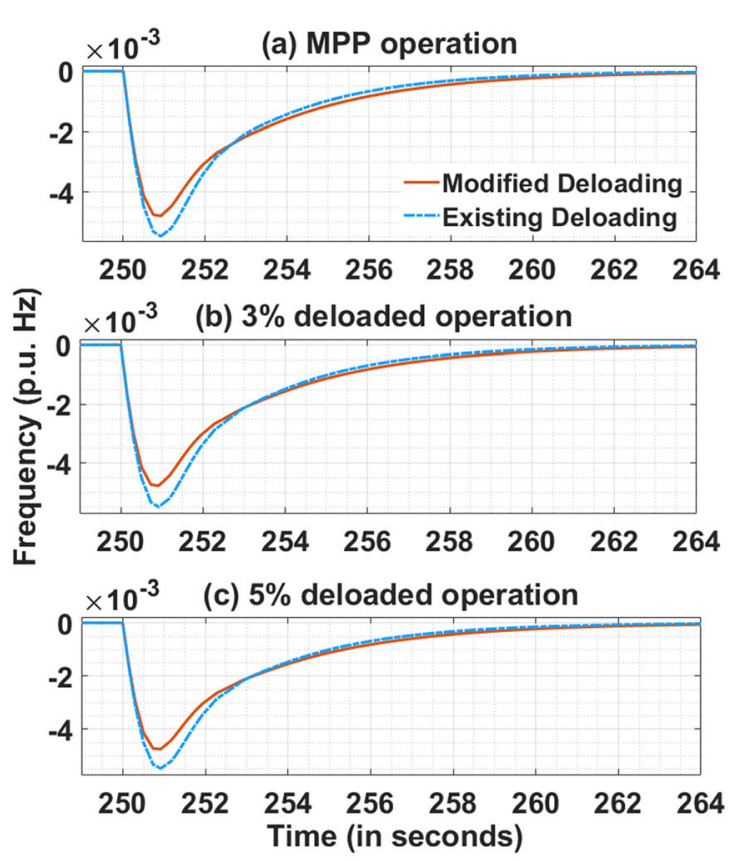

(B)

operation (B) For 15\% load rise during (a) MPP operation, (b) 3\% deloaded operation and (c) $5 \%$ deloaded operation 
Fig. 9 Reference power obtained with modified deloading (10\%) in response to step variation in wind speed and load
$P_{r e f}^{\prime}=\frac{W Z}{\omega_{r_{\text {opt }}}} \cdot\left(\omega_{r_{\text {meas }}}\right)^{2}+Z(1-W) \cdot \omega_{r_{\text {meas }}}$

\section{Simulation Results}

The proposed equation using curved trajectory is used to calculate the new reference power. Since, the reserve margin created during deloading is the difference between $P_{o p t}$ and $P_{r e f}$, so this difference plays a pivotal role in deciding the role of WTG in primary frequency contribution (PFC) in MG during under frequency events. A rise in this margin means the probability of WTG to participate in PFC is more, while a low power margin decreases the probability of PFC of WTG. Also the reference power play an important role to decide the available power margin. The more the reference power with respect to rotor speed the lesser is the frequency deviation in MG, but at the same time the power margin reduces which means the probability of WTG to participate in PFC is reducing.

After deloading, WTG operates below maximum power point and creates a reserve margin which may be utilized during low frequency conditions in MG by increasing the reference power of WTGs. In order to monitor this energy reserve the WTGs rotor speed of WTG is adjusted to modify the reference power of WTG that is being supplied to the MG for overcoming the power deficiency. The maximum and minimum limits of the reference power are $P_{\max }$ and $P_{\text {del }}$. To change the reference power of WTG, the rotor speed has to be altered. Assuming the straight line trajectory in Figure 2, the equation (2) have been used to calculate the reference power of WTG with varying rotor speed of WTG. Whenever the load in MG changes, the wind turbine rotor speed is altered to match the reference power as required by MG. The rotor speed in response to wind speed and load changes has been shown in Figures 5 and 6 . The rotor speed depends upon wind speed and load change in MG. Major change in rotor speed is directly proportional to wind speed which occurred at 50th, 150th' and 250th seconds. The load rise takes place in MG at 100th, 200th, and 300th second while a fall in load occurs at 400th second. Figure 5, Figure 6(a) and 6(b) depicts that the rotor speed is directly proportional to wind speed and inversely proportional load change in MG. For load rise in MG the turbine rotor speed fall to raise the reference power in order to compensate for the increased power demand from the MG during depressed frequency situations.
Fig. 10 Turbine rotor speed comparison for the linear modified deloading for wind speed change and load change

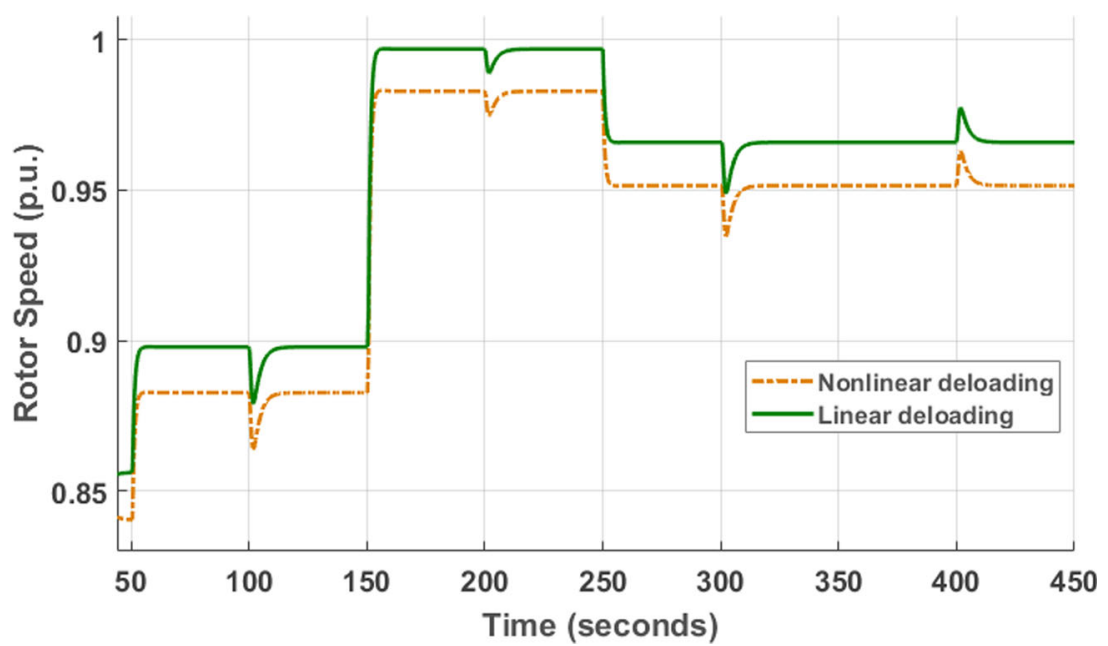


Table 1 Load frequency response in MG with controlled reference power and rotor speed of WTG

\begin{tabular}{llll}
\hline $\begin{array}{l}\text { Load } \\
\text { (p.u.) }\end{array}$ & $\begin{array}{l}\text { Frequency } \\
\text { (p.u.) }\end{array}$ & $\begin{array}{l}\text { Rotor speed } \\
\text { (p.u.) }\end{array}$ & $\begin{array}{l}\text { Reference Power } \\
\text { (p.u.) }\end{array}$ \\
\hline $\boldsymbol{P}_{\boldsymbol{l f}} \boldsymbol{P}_{\boldsymbol{l i}}$ & $\Delta f$ & $\omega_{f} \omega_{i}$ & $P_{\text {reff }} P_{\text {refi }}$ \\
$1.3-1.2$ & -0.005 & $0.875-0.894$ & $0.0942-0.0932$ \\
$1.45-1.38$ & 0.0035 & $0.9745-0.963$ & $0.1017-0.1026$ \\
\hline
\end{tabular}

Figure 7 shows the plots for maximum power $P_{\max }$, the deloaded power $P_{d e l}$ and the reference power $P_{\text {ref }}$. According to [5] the reference power should lie between $P_{\max }$ and $P_{d e l}$, but here it can be clearly observed that $P_{\text {ref }}$ is not within the specified stable range for the given wind speed. Hence following the equation (4) of straight line trajectory for calculating the $P_{\text {ref }}$, need modification. In further simulation the speed of wind is increased and the reference power as well as turbine rotor speed has been observed. It has been found that using the linear deloading the reference power lies between $P_{\max }$ and $P_{d e l}$ when the wind speed is increased to 150 to $180 \%$ of the current wind speed. Hence it can be inferred that linear deloading is applicable for higher wind speeds.

\section{Frequency Regulation against Load Variation in MG}

The percentage of deloading has direct effect on the peak frequency deviations in MG against load variation. In order to study this effect, the wind turbine has been operated in MPP mode and deloaded mode (3\% and 5\%). Due to operational constraints the deloadings more than $5 \%$ are unfeasible and unrealistic in practice. While WTG operating in deloaded mode the load in MG has been increased by $10 \%$ and $15 \%$ and its effect on frequency deviation has been recorded. The frequency deviation obtained with modified and existing deloading methods have been plotted together in Figure 8 for MPP, 3\% deloading and 5\% deloding. Observing the frequency deviation plots obtained by existing and proposed (modified) deloading techniques, it can be stated that the proposed method improves

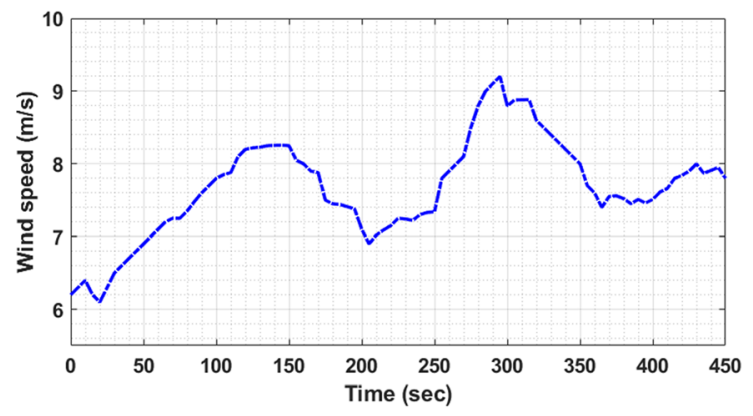

(a) the current practice of deloading the WTGs for frequency regulation in $\mathrm{MG}$.

\section{Modified Deloading: Comparison and Discussion}

The modified deloading differ from existing deloading in the strategy of deriving the equation to calculate reference power. The equation for modified deloading is derived by assuming the curved trajectory between $P_{o p t}$ and $P_{d e l}$. The equation relates the reference power of the wind turbine with the rotor speed of the turbine during the deloaded operation of WTG. The derived equation (13) has been used here to calculate the reference power with respect to measured rotor speed. The proposed method is tested with step and random variation in wind speed.

Deloading phenomenon allows WTGs to respond to MG frequency deviation by altering their reference power supplied to it during disturbances like sudden load rise or loss of generation. For a WTG the deloading upper limit is $P_{o p t}$ and lower limit is $P_{d e l}$. When deloading initiates, the reference power of WTG is varied between the $P_{o p t}$ and $P_{d e l}$. The modified deloading method is simulated and analyzed for step variation in wind speed and load variations. Figure 9 shows the power pattern for maximum, deloaded and reference power for the proposed deloading method. As stated earlier that the reference power should lie between $P_{o p t}$ and $P_{d e l}$ which is verified with the simulation result in Figure 9. The corresponding rotor speed is shown in Figure 10 and it is within the maximum allowable range for stable rotor dynamics. It can be observed from Figure 10 that for load rise at 100th second, the rotor speed of WTG falls and for a load fall at 400th second in MG the rotor speed of WTG rises to alter the power contribution of WTG for supporting the frequency regulation in MG. It is also observed that the rotor speed is less in case of modified deloading technique while it is more for linear deloading method for same deloading factor. However, in both the methods the rotor speed remains well within the stable range of operation.

The pattern of WTG power, power margin and rotor speeds are analyzed to do comparative analysis between the linear and

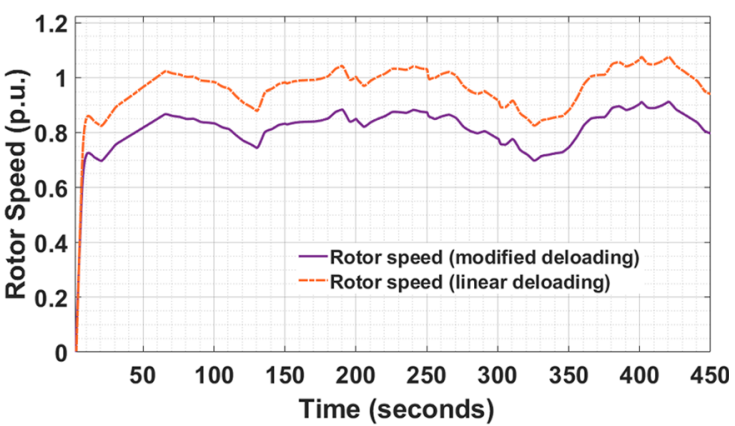

(b)

Fig. 11 (a) Random wind speed applied to WTG (b) Rotor speed in linear and modified deloading methods 


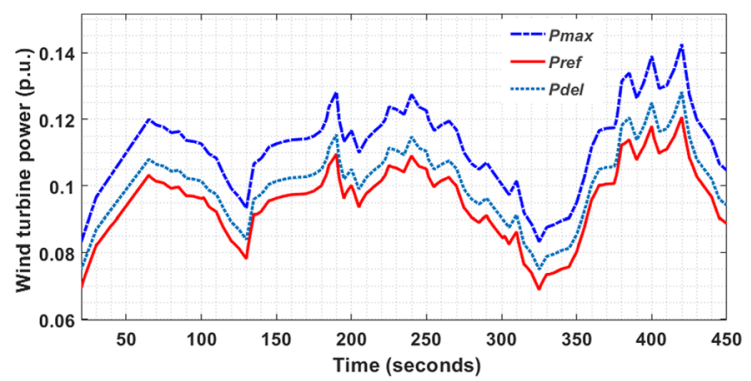

(a)

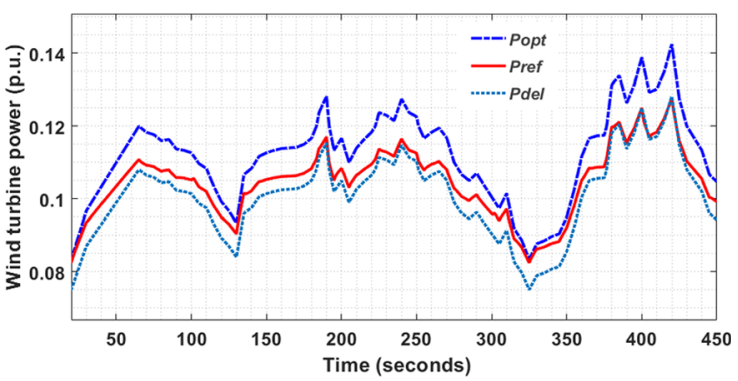

(b)

Fig. 12 WTG power variation in response to random wind speed with (a) linear deloading technique (b) modified deloading technique

modified deloading. The accurate calculation of reference power is very important during dynamic situations to get accurate estimate of power margin available. The more power margin means that a deloaded WTG can participate in PFC for longer duration as well as it can share in larger amount. In this work, the modified deloading represents the real-time scenario very closely with more frequency support capability to MG along with the stable rotor dynamics of the wind turbine. The observation Table 1 shows the data related to WTG participation in $\mathrm{MG}$ frequency regulation i.e. in response to load change in MG the frequency of the MG deviates. The WTG takes frequency deviation as an input and in response adjusts its rotor speed to change the reference power for compensating the power change in MG. The load power is denoted as $P_{l}$ where, $P_{l f}$ and $P_{l i}$ are the final and initial load power. Frequency deviation in denoted as $\Delta f$ while rotor speed and reference power are denoted as $\omega$ and $P_{r e f}, \omega_{f}$ and $\omega_{i}$ are the final and initial rotor speed. Reference power of wind turbine is denoted as $P_{\text {ref }}$ where $P_{\text {reff }}$ and $P_{\text {refi }}$ are the final and initial reference power of wind turbine generator. Table 1 presents two cases where the first case is related to load rise and second case is related to load fall. In the cases where the load demand in the MG rises and the frequency goes below nominal, to regulate the frequency deviation the WTG rotor speed decreases to increase the reference power of WTG for supplying to the MG.

\section{Modified Deloading for Random Pattern of Wind Speed}

A random wind speed shown in Figure 11(a) is applied to the WTG. The rotor speed of turbine in response to random wind speed has been shown in Figure 11(b) for two different deloading strategies i.e. linear and modified. The rotor speed change obtained for modified deloading is less as compared to linear deloading.

The power response of WTG against the random wind speed pattern is shown in Figure 12(a) for linear deloading and in Figure 12(b) for modified deloading. Unlike linear deloading, during the modified deloading operation the reference power is varying within allowable power range i.e. $P_{\text {opt }}$ and $P_{d e l}$ and the rotor speed is not exceeding the limit.

\section{Real-Time Hardware-in-Loop (HIL) Validation}

The real-time HIL simulator is the effective tool for testing the real-time performance of the models/controllers for power system and microgrid applications. The complex mathematical models of wind turbines and MG requires a very small time step for its accurate analysis. Real-time implementation of the proposed deloading method has been carried out using Opal-RT real-time digital simulator (OP4510) with a time step
Fig. 13 Experimental set up for validation of proposed method with digital simulator OpalRT4510

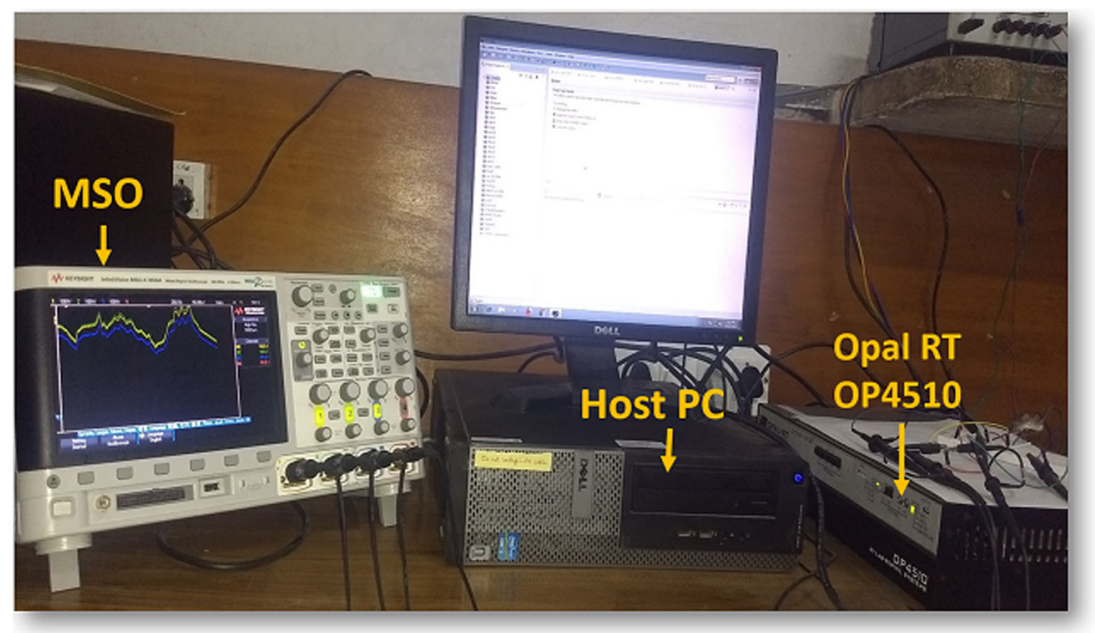




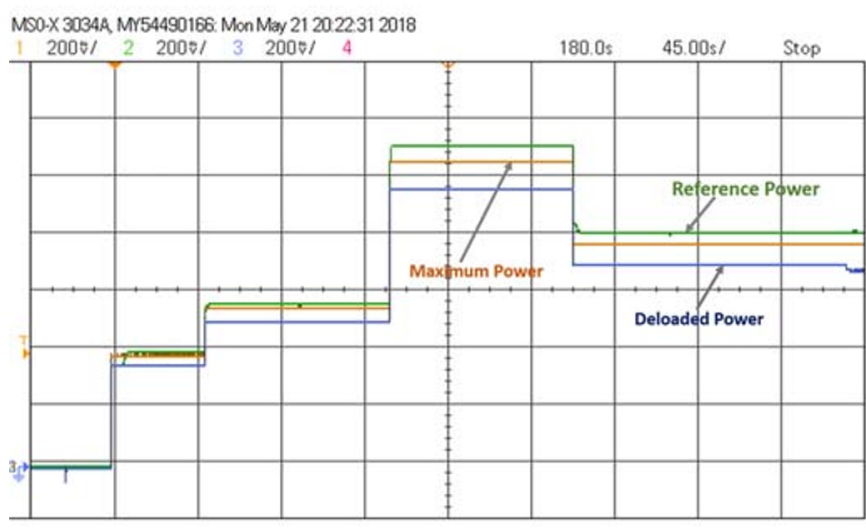

(a)

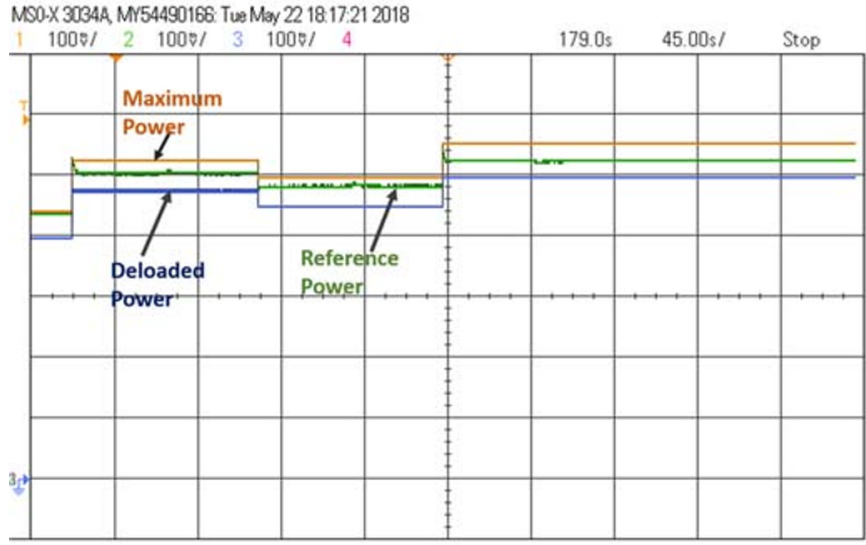

(c)

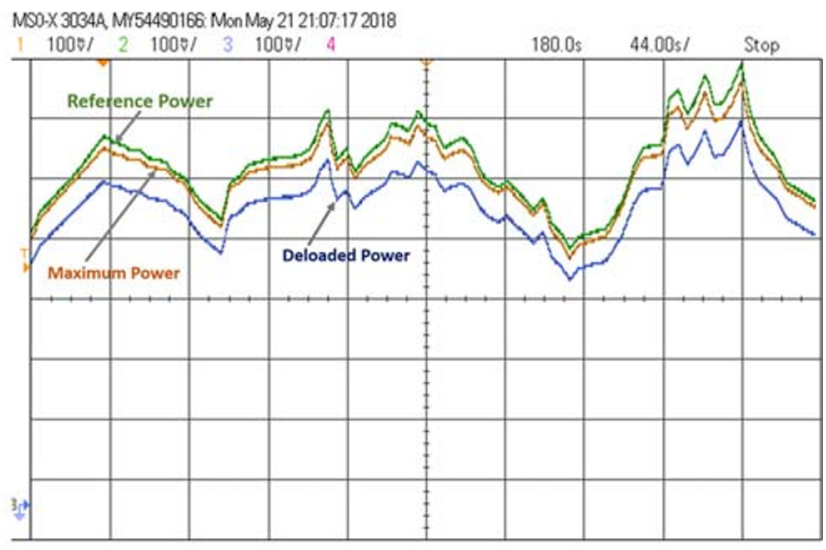

(b)

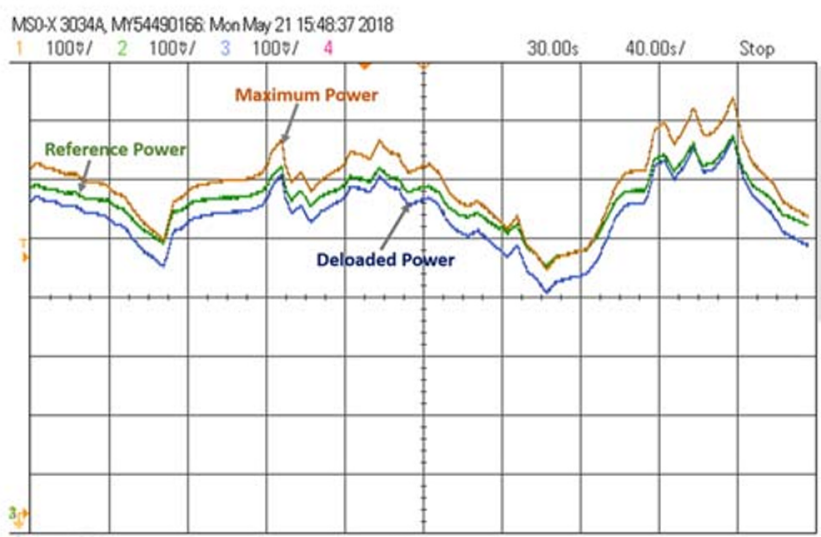

(d)

Fig. 14 Real-time validation results of deloading techniques for different pattern of wind speed variation (a) linear deloading for step variation in wind (b) linear deloading with random wind variation (c) Modified deloading for step variation (b) Modified deloading for random wind variation

of $50 \mu \mathrm{S}$. MATLAB/Simulink model of the wind turbine based MG system is built on real-time simulator through RT-Lab software interface. The experimental set up for real-time validation is shown in Figure 13.

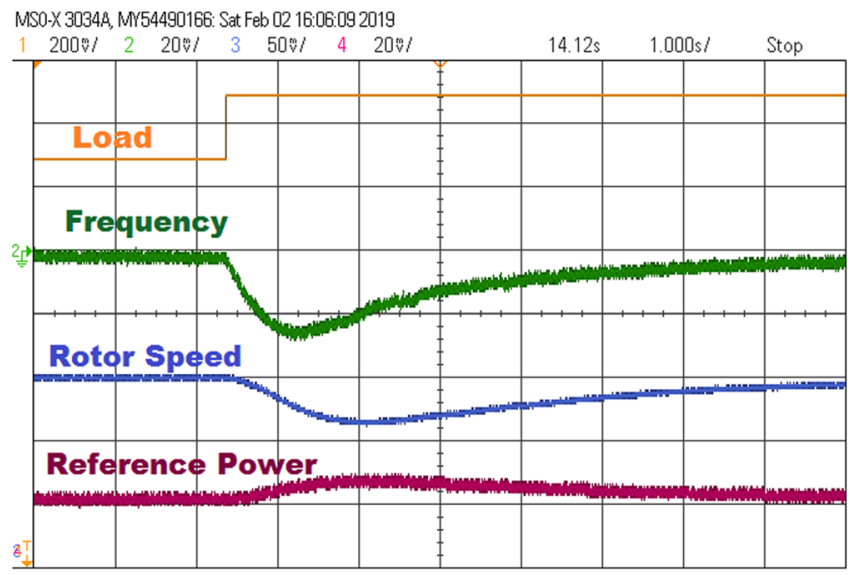

(a)
Firstly the validation of linear deloading method has been done to verify the trend of reference power $\left(P_{r e f}\right)$ that should vary between maximum power $\left(P_{\max }\right)$ and deloaded power $\left(P_{d e l}\right)$. The Figure 14 show the real-time HIL implementation

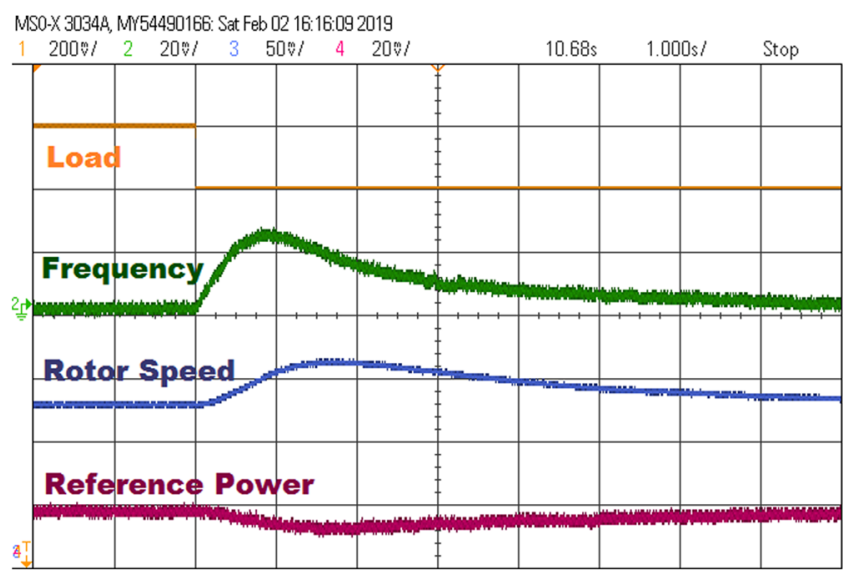

(b)

Fig. 15 Real-time validation results for load power variation in MG and corresponding dynamics in WTG for modified deloading method (a) Load rise effect (b) Load fall effect [Scale: Load (0.1 p.u./div), Frequency (0.004 p.u./div), Rotor Speed (0.1 p.u./div), Reference Power (0.004 p.u./div)] 
results for existing and modified deloading method of WTGs to participate in the frequency regulation of MG. The real-time simulation has been done taking three different scenario.

\section{Scenario 1: Real-Time Implementation of Linear Deloading}

The Figures 14 (a) and 14(b) show the wind power (maximum power, deloaded power and reference power) against the step and random variation in wind speed for linear deloding method. It is observed that the reference power obtained by linear deloading computation is crossing the allowable power range for variations in wind speed. This contradicts the theory that, while deloading the reference power must lie within the allowable range i.e. between $P_{\max }$ and $P_{d e l}$ at any instant.

\section{Scenario 2: Real-Time Implementation of Modified (Non-Linear) Deloading}

The Figures 14(c) and 14(d) show the wind power (maximum power, deloaded power and reference power) against the step and random variation in wind speed for modified deloading method. It is observed that the reference power obtained by modified deloading computation never cross the allowable power range (allowable range i.e. $P_{\max }$ and $P_{d e l}$ ) for variations in wind speed. This proves the accuracy of modified deloading technique, since the reference power is varying between $P_{\max }$ and $P_{d e l}$.

\section{Scenario 3: Real-Time Implementation of Frequency Regulation in MG with Modified Deloading}

To validate the modified deloading technique, two different cases have been considered for experiment. During HIL experiment the MG consisting WTG is subjected to a step load rise and fall and the dynamics of parameters like frequency of $\mathrm{MG}$, rotor speed of wind turbine and reference power output of WTG obtained for modified deloading operation have been recorded. Figure 15(a) shows the load rise case while Figure 15(b) shows the load fall scenario. The complete Simulink model of wind based MG is built on the real-time simulator and the external load disturbance signal is applied to model for studying the effect of load rise and fall in wind based MG. In Figure 15(a) it has been observed that for step load rise in MG the frequency falls and in response the turbine rotor of WTG reduces its rotor speed by releasing the stored kinetic energy to increase the overall reference power share to the MG. In Figure 15(b), it has been observed that for step load fall in MG the frequency shoots up and in response the turbine rotor of WTG absorbs the kinetic energy by accelerating and hence, the reference power share to MG reduces.

\section{Conclusion}

The linear deloading strategy of WTGs has been studied and modified considering the non-linearity in the system dynamics. A more accurate method for deloading of wind turbines has been derived to enable its participation for load frequency control in wind-diesel based microgrid. The non-linear trajectory between the maximum and deloaded power point has been formulated, simulated and validated in real-time simulator. The frequency deviation results of MG obtained with modified deloading are compared with existing deloading method and it is showing improved behaviour. The increased reference power of WTG obtained with modified deloading is fed to MG for balancing the increased load demand that results in further reduction in frequency deviation. The accurate estimate of reference power of the deloaded WTG has improved the transient stability as well as the primary frequency contribution to MG. The derived equation of modified deloading technique presents more accurate analysis of the turbine rotor speed versus power characteristics. The simulation model of complete system has been built on real-time simulator and the proposed deloading technique is validated with real-time HIL results. The HIL results shows improved contribution of deloaded WTGs for primary frequency control in MG.

\section{References}

1. Spear S. Wind energy could generate nearly 20 percent of world's electricity by $2030 ; 2014$. Available from: https://www.ecowatch. com/wind-energy-could-generate-nearly-20-percent-of-worlds. html

2. Bansal RC (ed) (2017) Handbook of distributed generation: electric power technologies, economics and environmental impacts. Springer, Cham, Switzerland

3. Bansal RC, Bhatti TS, Kothari DP (2001) Some aspects of grid connected wind electric energy conversion systems. Interdisciplinary Journal of Institution on Engineers (India) 82(1): 25-28

4. IEA. Solar leads the charge in another record year for renewables; 2017. Available from: https://www.iea. org/publications/ renewables 2017

5. Vidyanandan K, Senroy N (2013) Primary frequency regulation by deloaded wind turbines using variable droop. IEEE Transactions on Power Systems 28(2):837-846

6. De Almeida RG, Lopes JP (2007) Participation of doubly fed induction wind generators in system frequency regulation. IEEE Trans Power Syst 22(3):944-950

7. Ramtharan G, Jenkins N, Ekanayake J (2007) Frequency support from doubly fed induction generator wind turbines. IET Renewable Power Generation 1(1):3-9

8. Kayikci M, Milanovic JV (2009) Dynamic contribution of DFIGbased wind plants to system frequency disturbances. IEEE Trans Power Syst 24(2):859-867 
9. Chang-Chien LR, Lin WT, Yin YC (2011) Enhancing frequency response control by DFIGs in the high wind penetrated power systems. IEEE Trans Power Syst 26(2):710-718

10. Erlich I, Wilch M. Primary frequency control by wind turbines. In: Power and Energy Society General Meeting; IEEE; 2010

11. Wang P, Billinton R (2001) Reliability benefit analysis of adding WTG to a distribution system. IEEE Transactions on Energy Conversion 16(2):134-139

12. Subramanian C, Casadei D, Tani A, et al. EMS'13: Proceedings of the European Modelling Symposium. Vol. 1; Washington, DC, USA. IEEE Computer Society; 2013. p. 426-431

13. Keung PK, Li P, Banakar H et al (2009) Kinetic energy of windturbine generators for system frequency support. IEEE Transactions on Power Systems 24(1):279-287

14. El Mokadem M, Courtecuisse V, Saudemont C et al (2009) Fuzzy logic supervisor-based primary frequency control experiments of a variable-speed wind generator. IEEE Trans Power Syst 24(1):407417

15. Castro LM, Acha E (2018) A new method to assess the contribution of VSC-HVDC connected wind farms to the primary frequency control of power networks. Electr Power Syst Res 154:48-58

16. Bhateshvar Y, Mathur H, Siguerdidjane H (2015) Impact of wind power generating system integration on frequency stabilization in multi-area power system with fuzzy logic controller in deregulated environment. Frontiers in Energy 9(1):7-21

17. Chen Y, Xu Z, Stergaard J (2013) Islanding control architecture in future smart grid with both demand and wind turbine control. Electr Power Syst Res 95:214-224

18. Bao YQ, Li Y (2015) On deloading control strategies of wind generators for system frequency regulation. International Transactions on Electrical Energy Systems 25(4):623-635

19. Holdsworth L, Ekanayake JB, Jenkins N (2004) Power system frequency response from fixed speed and doubly fed induction generator-based wind turbines. Wind Energy: An International Journal for Progress and Applications in Wind Power Conversion Technology 7(1):21-35

20. Bhateshwar YK, Mathur HD, Bansal RC (2017) Power-frequency balance in multi-generation system using optimized fuzzy logic controller. Electric Power Components and Systems 45(12):12751286

21. Bhateshwar YK, Mathur HD, Bansal RC (2017) Ant colony optimized fuzzy control solution for frequency oscillation suppression. Electric Power Components and Systems 45(14):1573-1584
22. Bansal RC, Bhatti TS (2008) Small signal analysis of isolated hybrid power systems: reactive power and frequency control analysis. Alpha Science International, Oxford UK

23. D'iaz-Gonz'alez F, Hau M, Sumper A, et al. Coordinated operation of wind turbines and flywheel storage for primary frequency control support. International Journal of Electrical Power \& Energy Systems. 2015;68:313-326

24. Fang K, Zhang W, Bai X, et al. Load frequency control participation of wind farms in power systems. In: IEEE PES Innovative Smart Grid Technologies Conference (ISGT); 6-9 Sep. 2016. p. 1-5

25. Singarao VY, Rao VS. Economic analysis of reserve management strategies for grid-connected wind farms. International Journal of Power and Energy Systems. 2015;35(3)

26. Pradhan C, Bhende C (2015) Adaptive deloading of stand-alone wind farm for primary frequency control. Energy Systems 6(1): 109-127

27. Pradhan C, Bhende CN (2016) Enhancement in primary frequency regulation of wind generator using fuzzy-based control. Electric Power Components and Systems 44(15):1669-1682

28. Dreidy M, Mokhlis H, Mekhilef S (2017) Inertia response and frequency control techniques for renewable energy sources : a review. Renew Sust Energ Rev 69:144-155

29. Marinelli M, Massucco S, Mansoldo A et al (2011) In: analysis of inertial response and primary power-frequency control provision by doubly fed induction generator wind turbines a small power system; 17 th power systems computation conference. Stockholm, August $22-26$

30. Ducar I, Marinescu C, Serban I. Modified MPPT control for small wind turbines to provide dynamic frequency support in islanded microgrids. In: IEEE 6th International Conference on Clean Electrical Power (ICCEP); 2017.p. 298-303

31. Kumar D, Mathur HD, Bhanot S, Bansal RC Modeling and frequency control of community micro-grid under stochastic wind and solar sources. Accepted for publication in JESTECH

32. Kumar D, Mathur HD, Bhanot S, Bansal RC (2019) Frequency regulation in islanded micro-grid considering stochastic model of wind and PV. Int Trans Electrical Energy Systems 29(9):e12049

33. Kundur P, Balu NJ, Lauby MG (1994) Power system stability and control. McGraw-Hill, New York USA

Publisher's Note Springer Nature remains neutral with regard to jurisdictional claims in published maps and institutional affiliations. 